\title{
Practitioner Report
}

\section{Operant Procedures Applied to a Conversion Disorder}

\author{
Pieter F. M. Kop* \\ Hanno P. van der Heijden \\ Kees A. L. Hoogduin ${ }^{1}$ \\ Cas P. D. R. Schaap \\ University of Nijmegen, The Netherlands
}

\begin{abstract}
Conversion symptoms, as identified by the existing classification systems, do not form a single unitary class. It is therefore difficult to find an adequate treatment that closely connects to the basic characteristics of the disease. Instead, we designed a treatment method that closely relates to the behavioural aspects of a conversion disorder. We reasoned that motor patterns can be taught straightforwardly by means of operant conditioning methods and that movement disorders in conversion should be treated accordingly. Our case study shows that carefully retraining deficient motor patterns may constitute the core of the treatment for conversion disorders.
\end{abstract}

\section{INTRODUCTION}

According to most classification systems of diseases (DSM-III-R, (APA, 1987); ICD-9) physical symptoms are the principal manifestation of conversion disorders. Also, in the terminology of psychiatric classifications, the emphasis is placed on the physical aspects of somatoform disorders of movement. The disease presents as physical illness or discomfort in the absence of consistent physical pathology. At the same time the assessed psychological deficiencies and the patient's complaints are closely related. In addition, the patient is unaware of possible causes other than physical ones, and the symptoms are not culturally sanctioned or limited to pain or a disturbance of sexual functioning. Understandably, a definition that depends on exclusions is elusive and proper diagnosis without positive findings gives rise to severe problems (Slater, 1965).

Firstly, the aspects of physical symptoms should

\footnotetext{
${ }^{1}$ Addressee for correspondence: C. A. L. Hoogduin, Department of Social Sciences, Division of Clinical Psychology, P. O. Box 9104, $6500 \mathrm{HE}$ Nijmegen, the Netherlands.

*Now at: Nederlands Centrum voor de Geestelijke Volksgezondheid, Utrecht.
}

be assessed and exclusion of physical pathology is a requirement that logically and practically can never be met. But even when contemporary absence of physical pathology can be satisfactorily ascertained, it does not exclude earlier involvement of physical ailment in establishing a conversion. Secondly, there are no obvious reasons to exclude non-physical sources of conversion merely because a positive finding of physical pathology has been established. Particularly when a diagnosis is in any way relevant for developing a treatment method, it makes little sense to disclaim systematically other sources of pathology. Thirdly, the 'in the absence' definition and description of conversion disorders fails to acknowledge that the symptoms may be originated and maintained by several psychogenic determinants, either simultaneously, or in succession (Marsden, 1986). Anxiety, depression and obsessivecompulsive disorders may be critically related to bodily dysfunctions (Klerman, 1982; Fahn, and Williams, 1988; Marsden, 1989). Ideally, the treatment of a conversion disorder reflected in the motor system should depend on the proper identification of the primary source of disturbance.

We propose that, once medical procedures and 
interventions to cure a movement disorder have been exhausted, these procedures be gradually abandoned and treatment is concentrated on the behavioural manifestations of the disorder. Psychological problems should subsequently be treated as they appear and to the extent that they are acceptable to the patient. Eysenck and Rachman (1965) have described several applications of conditioning methods to the treatment of conversions and hysterical disorders. Many of the early applications are devoted to establishing a classically conditioned stimulus to increase patients' ability to perceive stimuli, as in hysterical deafness or blindness or anaesthesia. In addition classical conditioning has been applied to induce avoidance reactions in hitherto paralysed limbs. Wolpe's (1958) special training for low anxiety hysterics included some training methods for motor patterns, but his main treatment was the application of anxiety reducing techniques as systematic desensitization, based on classical conditioning. Somewhat similar, Dollard and Miller (1950) proposed that hysterical disorders are learned because the symptoms reduce the fear drive, and treatment should concentrate on anxiety reduction by other means. A promising therapy has been the use of suggestive strategies (Hafeiz, 1980), including hypnosis. In symptom directed hypnosis (van Dijck and Hoogduin, 1989, 1990; Hoogduin and van Dijck, 1990) a state of heightened suggestibility is created so as to influence symptoms in a positive way. It seems that behavioural treatment plays an important and essential part in symptom directed procedures.

When conversion disorders are treated with hypnotherapeutic methods shaping, chaining and reinforcement also play an important role. It is not an essential requirement of behaviour therapy that a patient be conscious or aware of the treatment in order for it to be efficacious: hypnosis by no means bars operant techniques from being effective. It would seem reasonable to investigate the sole use of a strict behavioural treatment as a therapy for conversion disorders classified as a movement disorder. Behaviour therapy has traditionally put strong emphasis on the behavioural aspects of mental disorders rather than on the defining characteristics. In part, behavioural treatment plans may be developed before a definitive causative analysis has been completed.

We have investigated one case of a conversion disorder and have carried out the treatment according to the methods and principles of behaviour therapy. The movement disorder of the present patient involved the inability to chew food. The eating prob- lem did not have an apparent anatomical or neurological cause and was not successfully treated by conventional medical procedures. To the extent that diagnosis could be ascertained, the movement disorder could best be classified as a conversion disorder. For the present purposes we made a detailed study of the exact movements and designed a plan to train and improve the detailed movements of tongue, facial musculature and jaws, and to chain these movements together into the appropriately coordinated action that is called biting and chewing' as it precedes swallowing in normal eating.

\section{CASE REPORT}

A 55-year-old woman, married to a pediatrician and mother of grown-up children still living at home, presented with the problem above. She was able to take small bites from pieces of solid food, but was apparently unable to chew it into small parts that could be swallowed. When she tried eating and dividing the food between the right and left pouches her jaws would start an uncontrollable tremor that prevented the food from being moulded into smaller parts and from being chewed and digested. Typically, the food would fall out of her mouth as she was unable to keep her lips together while eating. She would dribble bits of wet food onto her clothes. She was grossly disgusted by what she felt was an ugly and unappetizing sight, and she usually covered her mouth with her right hand while eating. She normally avoided eating at the family table and would eat later after dinner sessions in the kitchen where nobody could see her. She was also unable to attend the usual social functions associated with her husband's position. The problem had existed for more than eight years and had caused considerable stress, for herself as well as for her family members, and had so far been unsuccessfully treated by a neurologist, otolaryngologist, physiotherapist, hypnotherapist, manual physician, homeopathic physician, and various consultants from the non-medical professions.

Preceding the development of the eating problem she had suffered from an uncontrollable paralysis: she was unable to prevent her eyelids from closing, which made it impossible to drive a car or ride a bicycle, and even walking the street alone was dangerous. She was able to see by tilting her head backwards and looking out from under her eyelids. A diagnosis of blepharospasm requires a complete closure of the eyelid musculature and the patient being unable to look out from under the eyelids. Not 
only was this not so in this woman's case, but also when she consulted a neurologist, a psychiatrist and an opthalmologist, the symptoms disappeared entirely. These facts do not, then, support the diagnosis of blepharospasm. The onset of the eyeclosure problem was unrelated to any particular incident, and it disappeared after about five months, only to be replaced very shortly afterwards by the eating problem.

There remains the possibility that the patient's symptoms may be classified as oromandibular dystonia. But, first of all, the movement problem was an irregular tremor in which the jaws chattered, with, more or less independently, dyskinesia-like movements of the lips and tongue. These symptoms do not necessarily indicate dystonia. In addition, no further evidence for an oromandibular disorder was found in either phase of the illness.

In a test for sensitivity to hypnosis (Stanford Hypnotic Clinical Scale) she was found to be totally insensitive to hypnotic induction procedures and scored zero.

\section{Method}

The movement disorder was first studied live and from videotape recordings. The presentation of pieces of solid food into the mouth resulted in one or two small bites. Once the morsels of food had passed the front teeth and reached the tip of the tongue, the jaws would start the tremor. It sounded as if the patient was chattering with cold. Apparently, tongue manipulations and jaw movements lacked the coordination which would allow the division of the food over the two pouches or even just store it all on one side. Even when the food reached the vicinity of the molars the jaws were moving too quickly to allow proper mastication.

\section{The Training Programme}

The shaping and chaining programme to re-establish the proper eating movements consisted of the following steps that partly overlapped and partly followed one another. At first the patient was asked to press her lips together for a few seconds and then release them again. The exercise was intended to make the patient more aware of tension in oral and facial muscles. At the same time the patient was taught to press the molars tight together for a few seconds and then to release them again, in such a way that the upper and lower molars would no longer touch, but without opening the mouth or lips. We called this exercise 'tight jaws'.

When these exercises had been practised for two weeks during sessions and at home, three more exercises were introduced. The first exercise was later replaced by a more complex motor pattern. The patient was taught to almost open her mouth, barely keep her lips together and without the teeth clenching or even touching. The patient did these exercises with a plastic spoon between her lips so as to provide a visual feedback of the lip movements. She was told to keep the spoon hanging down and to hold it there without unnecessary movement. Also at this point she was asked to hum in a low voice, a middle voice and at a high pitch. The humming was to be rather loud, in one breath, and with closed lips. The exercise was intended to increase awareness of tension of the lips and oral musculature. In addition it helped to control breathing. The last exercise in this series was really an extension of the 'tight jaws' training: the patient was instructed to move her lower jaw up and down in the vertical plane and keep her jaws clenched just for a very brief period.

These latter exercises were practised first with empty mouth, next with water, then with yoghurt and then with more solid foods as fruits, sweets or chocolate, in that order. They were intended to teach the patient the exact position and tension of the lips and jaws and how to control the masseter muscles. The patient was asked not to chew and was forbidden to swallow the food. The patient was then instructed to move her jaws in opposite directions in the horizontal plane. This was the first exercise in which the masseter muscle must be permanently relaxed while other muscles induce the movement. The last two exercises were then combined: the patient was instructed to make circular movements with the lower jaw.

The last step introduced an exercise that involved biting, chewing and swallowing: (1) take a bite, followed by an absolute rest period of several seconds; (2) bite the piece of food in two parts and immediately thereafter regain control of all mouth musculature; (3) with your tongue, push one part to the left pouch and the other part to the right; (4) chew, i.e. make both vertical and horizontal movements with the lower jaw while keeping the tip of the tongue against the lower front teeth; (5) first relax all muscles and then collect the moist food and swallow. This five-step eating programme was to be practised using increasingly more solid foods: first yoghurt, then cake, banana, bread, chocolate, and so on.

During training sessions the patient was thoroughly rewarded and praised for any progress she made. She was made aware of all improve- 


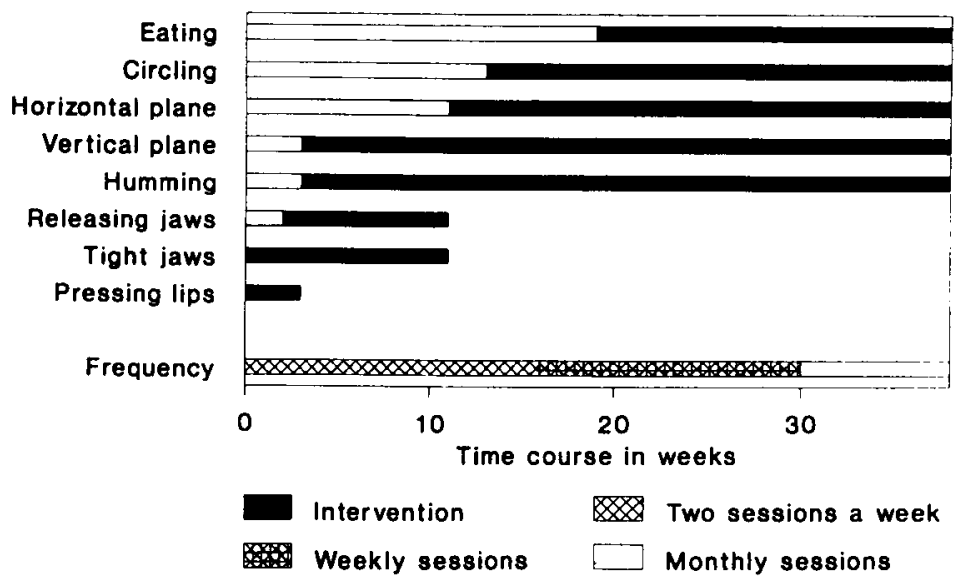

Figure 1. Horizontal black bars show the time course of successive treatment steps. After 15 weeks the session frequency was reduced from two weekly sessions to one session a week and after week 30 to monthly sessions. Treatment stopped after 38 weeks

ments, however slight, and was instructed to do her home exercises in front of a mirror and notice carefully any changes for the better. She was also asked to estimate each week how well she had felt and was praised for working hard on improving her wellbeing. Next to the shaping and chaining procedures the patient was provided with regulations to prevent undue strain and tension in daily life. During the first treatment session she learned to breathe slowly and quietly and was advised to take a few 10-min periods, every day, to lie or sit down to achieve a relaxed state and bring breathing under control. Thereafter the therapist only occasionally inquired whether the patient was still doing the breathing control. Another measure intended to prevent stress and strain, excitement or fatigue: a programme was scheduled that limited activities to a maximum by means of internal and external cues.

\section{Time Course}

The patient came to our treatment facility about twice a week during the first 15 weeks. Thereafter, weekly sessions were held until week 30 ; then monthly sessions were introduced. The first three steps of the shaping programme (pressing lips, tight jaws, and releasing jaws without opening the lips) were practised during sessions at home until week 11. The vertical and horizontal jaw movements were started during week 3 and 11 respectively. Practising was maintained throughout the treatment programme. Circling with the lower jaws, was begun during week 13 and similarly maintained. The last step, involving eating and chewing, was introduced during week 19. Figure 1 presents the time course of the successive training steps.

\section{Measurements}

Two sorts of measurements were taken: recordings to be judged by others, and self-monitoring of symptoms and behaviour. Video recordings were made of all training sessions. About every month an observation of normal drinking and eating was recorded. On these occasions the patient had to drink from a glass of water, in as orderly a manner as she was able to. Next she had to eat a piece of cake and similarly chew and swallow it to the best of her ability. The nine episodes were identified by a flower name (rose, lily and so on) and then randomly assembled on a single tape to be judged later. Each episode lasted about 90 s. Episodes were separated by a space of $15 \mathrm{~s}$ to allow the judges to write down their judgements. Eleven judges, all psychologists, were asked to do the rating. They were not familiar with the exact treatment programme nor with the patient. By way of introduction they were shown part of the intake interview which had taken place some weeks before treatment had started. During that interview the patient explained and demonstrated to the third author what she felt her exact complaints to be. The judges were to express their opinion on the aspects of the demonstrations of eating and drinking during the intake interview, on a seven-point Likert-scale. For drinking they were asked to rate smoothness of mouth/jaw movements and swallowing; and for eating: biting, chewing, tongue movements and swallowing. The judges 
were asked to report detailed observations so as to allow us to track the possible redevelopment of the presently lost eating and drinking movements. In addition, the judges were asked to express their overall opinion of drinking and eating on a Visual Analog Scale: the left side represented highly deficient eating and drinking with spastic movements and lots of spilling; the right side represented very neat eating that one might see in a chique restaurant. After proper understanding of the rating procedure had been ascertained, the judges were presented with the nine recorded observations.

On most days, at home, the patient marked what foods she had been able to eat properly. She was given a rating scale on which the foods were nominally ranked according to the difficulty she experienced eating them. E.g. yoghurt was very easy, followed by banana, then bread without crust, and the scale ended with french fries and chocolate. Every day she indicated the level at which she experienced no difficulty eating.

To monitor the general psychological complaints she experienced during the treatment period, the patient scored the SCL-90 questionnaire (Arrindell and Ettema, 1986) on four occasions.

\section{Results}

Figure 2 shows the overall ratings for drinking and eating, presented in chronological order. Drinking was already quite good during intake and still improved during treatment. Eating started at a very low and unsatisfactory level and gradually improved.

Mean ratings of drinking and eating correlated strongly with time of therapy. Spearman rank correlation $0.73(p<0.05)$ and $0.78(p<0.01)$ for drinking and eating respectively. Drinking correlated highly significantly with eating $(0.86, p<0.001)$. Since no obvious violations of the assumptions were apparent, a MANOVA for repeated measures, with one within subjects factor (time) was performed to detect differences during the therapy for the overall judgment of drinking and eating. This analysis showed a significant effect of time for the ratings of eating $(F(8,80)=10.44, p<0.001)$ and drinking $(F(8,80)=$ $5.68, p<0.001$ ) (since the assumptions of compound symmetry may not be fulfilled for drinking the Wilks Multivariate test may be applied: $F(8,3)=$ $14.41,(p<0.025))$. A polynomial transformation was performed to look for lineair and higher order trends. The variable for linearity showed a significant effect for both eating $(t(80)=5.90, p<0.001)$ and drinking $(t(80)=5.35, p<0.001)$.
From the results it can be concluded that progress in eating was observed by raters not familiar with the diagnosis and symptoms of the disorder. Interestingly, progress could also be observed for drinking, which was not the target of the training programme.

Further analysis of the detailed ratings showed that the general improvements were largely attributable to gradually better chewing $(t(80)=2.69, p<$ $0.05)$ and tongue movements $(t(80)=3.39, p<0.01)$. Biting remained somewhat hesitant throughout the entire treatment period $(t(80)=1.63, p=0.13)$ and swallowing was hard to observe from the video recordings.

The patient's own view of the progress she had made in eating matched quite closely the judges' ratings. During the initial phases of the treatment programme the patient could only eat soft food on the bottom of the scale. Later in training, the ease with which she ate improved, but never remained steady at the highest level on the scale.

The level of seriousness of complaints, as measured by the total score on the SCL-90 scale decreased from an initial 233 to 165 at the end of the treatment programme.

Unobtrusive measures were taken where possible. The most important of these was the level of contentment that the patient herself indicated. On several occasions she stated that her life had much improved since the treatment began, that she was able to go out and eat with family or friends in a restaurant and no longer had any reason to avoid eating in public. She felt that she still needed to be careful and that there was still progress to be made. She was confident that such progress was forthcoming and that she just needed more time. She mentioned that she was no longer afraid to go out with friends, that she felt free to visit and receive friends, and that she was very pleased with the results that she had achieved. She felt that her health generally had improved. She also stated that the bill for the cleaners had been much reduced, indicating that she only rarely now spilled food from her mouth. Interestingly, she said that she had been taking swimming lessons for years, but to no avail. No matter how hard she tried, she could not keep her head above the water. After she had learned to relax she was able to keep her head up, had quickly learned to swim, and now joins a group of women friends on their weekly trip to the pool.

Her husband confirmed her opinion of the results of the treatment. He volunteered that his wife was in a much better mood nowadays, and that they looked forward to vacationing a little more. He also noted 


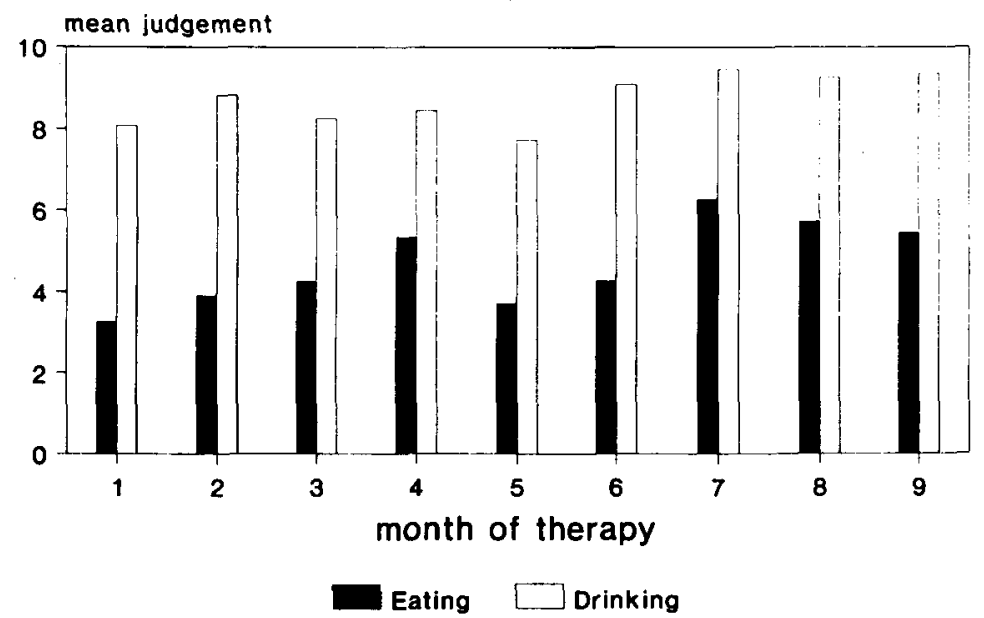

Figure 2. Histogram of judges' ratings of monthly recordings for eating (black bars) and drinking (open bars) episodes. The episodes were originally shown in random order, but are here presented chronologically

that his wife undertook more and was less compulsive: she encouraged the visit of overseas relatives and was less concerned when leaving the household and gardening chores unfinished.

The general conclusion from the recordings and other measures is that the movement disorder was improving gradually, and that the improvements were accompanied by a general improvement in well-being.

\section{Discussion}

We trained a patient with a (movement) conversion disorder to carry out eating movements properly and found that the patient responded favourably to simple operant procedures. Eating is a complex motor pattern. When parts of the complex pattern are wanting or deficient, analysis of the preceding and following motor patterns may be required. Together with training the lacking or deficient parts, reconnecting the movements in the proper order should suffice to rebuild the chain of movements that constitutes the behavioural episode of eating. The present case shows that careful training and shaping with the aid of sufficient feedback and reinforcement may bring back a lost motor pattern, for the loss of which no anatomical or physical pathology can be found. The findings are in agreement with conditioning theory: behavioural episodes can be built up (shaped) by training the composing parts separately and connecting (chaining) them by demanding ever greater precision and extension before the episode is reinforced.
Our case is not a unique instance of conditioning being involved in the maintenance or treatment of conversion movement disorders. We suggest that conditioning plays a role in the maintenance of conversion-phenomena, as well as in learning new behaviour to be substituted for undesirable behaviours. Part of the treatment must consist of abolishing environmental consequences for inappropriate maladaptive behaviour and arranging support for adaptive behaviour only (Kendell, 1982). It is easily demonstrated how the behaviours of patients with conversion disorders is directly influenced by antecedents and consequences of their symptoms. Munford and Liberman (1982) illustrate this by presenting the case of a 17-year-old girl who suffered from a chronic cough and mutism. They showed how the maladaptive behaviour (coughing) was maintained and how extinction reduced it. Next to reinforcement, extinction is crucial in conditioning processes. Extinction, or withholding reinforcement, does two things to behaviour: first it reduces the frequency of maladaptive behaviours. These behaviours are not eradicated but merely lose their importance. The second action of extinction is to increase the variety of the behavioural repertoire, i.e. it releases behaviour from rigid limitations and so facilitates the emergence of desirable behaviour. Our patient was discouraged from entertaining and receiving visitors as long as treatment lasted. She was told to concentrate on daily practice and to strictly attend to the treatment demands so as to withdraw social attention from the maladaptive behaviour. In doing this we also intended to create 
more room for and to put greater emphasis on the progress of appropriate eating behaviour. Her family members, relatives, friends etc. became more aware of the distinction between health and illness behaviour. That stimulated them to exclusively support the patient in her health behaviour. Her husband significantly changed his attitude and way of life and so reinforced healthy behaviour patterns in his wife. She repaid the reinforcing effects of his actions by becoming a more pleasant and interested wife.

Following extinction, the next phase in the behavioural treatment of movement disorders concerns the shaping of appropriate behaviour. Even when the behavioural repertoire has been liberated by directed extinction procedures and shows a greater variety of behaviour patterns, it does not always contain the necessary elements from which the desirable behavioural episodes can be shaped. Shaping may be seen both as building an ever longer sequence of behavioural elements, or as building up a sequence of repetitive behaviour. In the latter sense Munford and Paz (1978) trained a 62-year-old woman with a long history of astasia-abasia to make increasingly longer unsupported walks around a table. Similarly, in Munford and Liberman's case (1982) reinforcement duly increased their patient's speaking episodes, and so cured mutism. Mulder and Hoogduin (1986) described a 28-year-old patient with psychiatric aphonia (amongst many other complaints). The treatment was begun by instructing the patient to pronounce vowels while coughing. Next she was taught to utter one or more syllables with progressively less emphasis on the coughing and more on the pronunciation. After the patient had acquired the necessary elements (vowels, syllables) she soon learned to speak fluently. In our patient, eating and chewing movements first had to be shaped from smaller elements. Subsequently these elements were connected into behavioural patterns that eventually became what is defined as a desirable eating pattern.

Motor disorders, like the present one, can be treated with relatively simple training techniques. Success in training not only re-establishes defective motor capacities, it may also help the patient to regain his rightful place in society. Illness has a disabling effect on social life and has a large impact on the immediate social environment of the patient, particularly so when he has been suffering for many years. Illness has been part of life for years, and the environment expects the patient to be ill and stand aside when the more pleasurable social events take place. Social attention keeps the disorder perma- nently in focus at the cost of renouncing one's normal place in the family circle and the normal pleasures of life. Success in training and reward for positive efforts may help the patient to regain her rightful place in the family. When proper family and social functioning is made part of the treatment programme, it may assist greatly in reaching the therapeutic aims. The present programme demonstrated that simple conditioning methods helped the patient to overcome her motor problems and as a consequence she also learned to regain her place in the family. She learned to withhold signals about being ill and exceptional, and acquired more time and opportunity to attend to aspects of life that are in themselves rewarding.

\section{REFERENCES}

American Psychological Association (1987). Diagnostic and Statistic Manual of Mental Disorders (DSM-III-R), 3rd edn. revised. Washington, D.C.: American Psychological Association.

Arrindell, W. A. and Ettema, J. H. M. (1986). SCL-90. Handleiding bij een multidimensionele psychopathologieindicator. Lisse, The Netherlands: Swets \& Zeitlinger.

Dijck, R. van and Hoogduin, C. A. L. (1989). Hypnosis and conversion disorders. American Journal of Psychotherapy, 43, 480-493.

Dijck, R. van and Hoogduin, C. A. L. (1990). Hypnosis: placebo or nonplacebo? American Journal of Psychotherapy, 44, 396-404.

Dollard, J. and Miller, N. E. (1950). Personality and Psychotherapy. New York: McGraw Hill.

Eysenck, H. J. and Rachman, S. (1965). The Cause and Cures of Neurosis. An Introduction to Modern Behaviour Therapy Based on Learning Theory and the Principles of Conditioning. London: Routledge \& Kegan Paul.

Fahn, S. and Williams, D. T. (1988). Psychogenic dystonia. In S. Fahn, C. D. Marsden and D. E. Calne (Eds), $A d$ vances in Neurology, (Vol.50): Dystonia. New York: Raven Press, pp. 431-455.

Hafeiz, H. B. (1980). Hysterical conversion: A prognostic study. British Journal of Psychiatry, 136, 548-551.

Hoogduin, C. A. L. and Dyck, R. van (1990). Open trial with patients with conversion paralysis: results and follow-up. In W. Bongartz (Ed), Hypnosis: 175 Years After Mesmer. Konstanz: Universitaets Verlag, pp.411-418.

Kendell, R. E. (1982). A new look at hysteria. In A. Roy (Ed), Hysteria. New York: J. Wiley \& Sons, pp.2736.

Klerman, G. L. (1982). Hysteria and depression. In A. Roy (Ed), Hysteria. New York: J. Wiley \& Sons, pp. 211-228.

Marsden, C. D. (1986). Hysteria: A neurologist's view. Psychological Medicine, 16, 277-288.

Marsden, C. D. (1989). Movement disorders in neuropsychiatry. In E. H. Reynolds and M. H. Trimble (Eds), The Bridge Between Neurology and Psychiatry. Edinburgh: Churchill Livingstone, pp. 151-158.

Mulder, D. and Hoogduin, C. A. L. (1986). Behandeling 
van een psychogene afonie bij een patient met een somatisatie stoornis. Directieve Therapie, 3, 255-260.

Munford, P. R. and Liberman, R. P. (1982). Behavioural therapy of hysterical disorders. In A. Roy (Ed), Hysteria. New York: J. Wiley \& Sons, pp. 287-303.

Munford, P. R. and Paz, G. (1978). Differential attention in the treatment of astasia-abasia. Journal of Behavioral Therapy and Experimental Psychiatry, 9, 369-371.

Slater, E. O. (1965). Diagnosis of hysteria. British Medical Journal, 1, 1395-1399.

Wolpe, J. (1958). Psychotherapy by Reciprocal Inhibition. Stanford: Stanford University Press. 